\title{
Pediatric hydrocephalus: systematic literature review and evidence-based guidelines. Part 10: Change in ventricle size as a measurement of effective treatment of hydrocephalus
}

\author{
Dimitrios C. Nikas, M.D., ${ }^{1,2}$ Alexander F. Post, M.D., ${ }^{3}$ Asim F. Choudhri, M.D. $, 4,5$ \\ Catherine A. Mazzola, M.D., ${ }^{6}$ Laura Mitchell, M.A., ${ }^{7}$ and Ann Marie Flannery, M.D. ${ }^{8}$ \\ ${ }^{1}$ Department of Neurosurgery, University of Illinois at Chicago, Chicago, Illinois; ${ }^{2}$ Advocate Children's \\ Hospital, Oak Lawn, Illinois; ${ }^{3}$ Division of Pediatric Neurological Surgery, Department of Neurosciences and \\ Pediatrics, Goryeb Children's Hospital-Morristown Medical Center, Morristown, New Jersey; ${ }^{4}$ Departments \\ of Radiology, Ophthalmology, and Neurosurgery, University of Tennessee Health Science Center, and ${ }^{5}$ Le \\ Bonheur Neuroscience Institute, Le Bonheur Children's Hospital, Memphis, Tennessee; ${ }^{6}$ Division of Pediatric \\ Neurological Surgery, Goryeb Children's Hospital, Morristown, New Jersey; ${ }^{7}$ Congress of Neurological \\ Surgeons, Schaumburg, Illinois; ${ }^{8}$ Department of Neurological Surgery, Saint Louis University, St. Louis, Missouri
}

Object. The objective of this systematic review is to answer the following question: Does ventricle size after treatment have a predictive value in determining the effectiveness of surgical intervention in pediatric hydrocephalus? Methods. The US National Library of Medicine PubMed/MEDLINE database and the Cochrane Database of Systematic Reviews were searched using MeSH headings and key words relevant to change in ventricle size after surgical intervention for hydrocephalus in children. An evidentiary table was assembled summarizing the studies and the quality of evidence (Classes I-III).

Results. Six articles satisfied inclusion criteria for the evidentiary tables for this part of the guidelines. All were Class III retrospective studies.

Conclusions. ReCOMmEndATION: There is insufficient evidence to recommend a specific change in ventricle size as a measurement of the effective treatment of hydrocephalus and as a measurement of the timing and effectiveness of treatments including ventriculoperitoneal shunts and third ventriculostomies. STRENGTH OF RECOMMENDATION: Level III, unclear clinical certainty.

(http://thejns.org/doi/abs/10.3171/2014.7.PEDS14330)

KEY WORDS $\quad \bullet \quad$ hydrocephalus $\quad \bullet \quad$ ventricle size $\quad \bullet \quad$ evidence-based guidelines $\quad \bullet$
practice guidelines

$\mathrm{T}$ JHE decision to treat hydrocephalus with an external shunt or endoscopic third ventriculostomy (ETV) is based on a variety of factors. The determination of successful outcome rests on a multitude of clinical and imaging correlates. Imaging indicators that have been examined include ventricle size, presence of a flow void in the ETV site, amount of CSF over the cerebral hemispheres, and the degree of periventricular edema. The objective of this particular systematic review is to answer the question: Does ventricle size after treatment have a predictive value for effectiveness of surgical intervention in pediatric hydrocephalus?

Ventricle size before and after intervention is a readily available measurement that has been used to assess success or failure of treatment. Particular attention has been given to changes in ventricle size after ETV..$^{6,18,23}$

\footnotetext{
Abbreviations used in this paper: AANS = American Association of Neurological Surgeons; CNS = Congress of Neurological Surgeons; $\mathrm{CPC}=$ choroid plexus cauterization; $\mathrm{ETV}=$ endoscopic third ventriculostomy; FOR = frontal and occipital horn ratio; VP = ventriculoperitoneal.
}

Correlation with neurodevelopmental sequelae as well as correlation with other imaging parameters, such as presence of flow voids after ETV, have been suggested as indications of successful interventions. , $^{2,10,13,25}$ The evaluation of the effectiveness of treatment has therefore been limited because developmental outcomes are most applicable in infants and younger children and flow voids observed on MR images are applicable only to ETV treatment. This review, therefore, focuses on ventricle size as a tool, albeit a limited one, in the evaluation of the effectiveness of treatment. Ventricle size is an outcome that could be used to assess patients of all ages as well as both forms of intervention - the ventriculoperitoneal (VP) shunt and the ETV. The purpose of this evidence-based review is to critically examine data from the literature pertaining to change of ventricle size as a predictor of the success of surgical intervention.

\section{Methods}

We searched the US National Library of Medicine (PubMed/MEDLINE) and the Cochrane Database of 


\section{C. Nikas et al.}

Systematic Reviews for the period January 1966 through March 2012 using strategies listed below. The inclusion and exclusion criteria adhered to the protocol outlined in the methods section, Part 1, of these evidence-based guidelines. ${ }^{8}$

\section{Search Terms}

PubMed/MEDLINE

1. "Cerebrospinal Fluid Shunts" [MeSH] AND "Hydrocephalus"[Majr:noexp]

2. 1 AND ("Magnetic Resonance Imaging"[MeSH] OR “Tomography, X-Ray Computed”[MeSH] OR Ultrasonography[MeSH] OR imaging[tiab])

3.2 AND ("ventricular size"[TIAB] OR "ventricular dilation"[tiab] OR ventricle[tiab] OR ventricles[tiab])

4. Limit to Child ( $0-18$ years)

5. Limit to English and Humans

6. Limit 3 to Child ( $0-18$ years)

7. Limit to English and Humans

Number $=81$

Cochrane Database

1. MeSH descriptor Child

2. MeSH descriptor Infant

3. MeSH descriptor Hydrocephalus

4. MeSH descriptor Cerebrospinal Fluid Shunts

5. (MeSH descriptor Magnetic Resonance Imaging) or (MeSH descriptor Ultrasonography) or (MeSH descriptor Tomography, X-Ray Computed) or imaging

6. (1 or 2 ) and 3 and 4 and 5

7. 3 and 4 and 5

\section{Search Strategy}

An evidentiary table was constructed to facilitate data review and analysis by the Pediatric Hydrocephalus Systematic Review and Evidence-Based Guidelines Task Force.

For each article included in the evidentiary table, the study type, summary findings, and major conclusions were recorded, and a preliminary data class was assigned. The Task Force met to discuss the ranking of the evidence and the classification of data. Recommendations then were made based on the strength of the data in the evidentiary table. In these discussions, if a disagreement was encountered among members, a blinded vote was held and a consensus or majority opinion was reached.

\section{Search Results}

A total of 81 abstracts were screened and 18 full-text articles listed in the databases were retrieved for review (Fig. 1). The selection for review was based on the determination of evidence data relevant to the question of the effect of treatment on ventricle size. An examination of the reference lists of these 18 full-text articles yielded 4 additional articles that warranted full-text review. All 22 articles were read and reviewed in detail by the full Task Force. Sixteen articles were excluded based on predefined criteria, which are described in Part $1^{8}$ of the Guidelines. Six articles satisfied the inclusion criteria and form the basis for the evidentiary tables in this recommendation.

\section{Results}

The 6 articles that met the inclusion criteria and were selected for final review were all Class III retrospective studies (Table 1).

In 2000, Kulkarni et al. ${ }^{18}$ published the results of a retrospective, blinded observational study of a group of 29 children who had undergone ETV and whose ventricle size was assessed by 4 independent observers using the FOR (frontal and occipital horn ratio) both preoperatively and postoperatively (Table 1). Postoperatively, the mean reduction in ventricle size was $7 \%$ in cases that were deemed treatment failures ( 8 patients in whom symptoms either recurred or never resolved) and $16 \%$ in cases that were clinically successful (21 patients) -a result that was statistically significant ( $p=0.03$, t-test). The authors concluded that ventricle size appeared to be somewhat reduced in both groups of patients; however, the reduction was significantly greater among the clinically successful cases. The authors also assessed imaging correlates; they found that the presence of a flow void seemed to correlate with clinical success and its absence with clinical failure. The most significant limitation in this study is its retrospective nature. Surgeon bias, the linear measurement of ventricle size, and the variation in time when postoperative imaging was conducted were confounding factors.

In another retrospective study, published in 2009, Warf et al. ${ }^{24}$ described neurocognitive outcomes and ventricle volumes in infants with myelomeningoceles and hydrocephalus (Table 1). The same method was used to compare ventricle size in 55 children treated by ETV with choroid plexus cauterization (CPC), 19 children who received a VP shunt, and another 19 children who required no intervention. The mean FOR was similar among groups, with no significant difference between the untreated group and either the VP shunt or ETV with $\mathrm{CPC}$ group before treatment. The groups also were compared for neurocognitive outcomes, and no significant difference was identified. The FOR did not correlate with neurocognitive performance. Bias existed with respect to the VP shunt group because most patients had already experienced ETV with CPC failure. This is another nonrandomized study with the potential for strong confounding factors within treatment groups. A valid conclusion was that stable mild-to-moderate ventriculomegaly alone should not trigger intervention in an asymptomatic infant with a myelomeningocele.

Another Class III single-center retrospective study in the myelomeningocele population was published by Chakraborty et al. ${ }^{4}$ in 2008 (Table 1). These authors studied 28 patients who were selected from a group of 54 who satisfied the determined inclusion criteria. Overall, using a stringent shunt placement policy, about half $(51.9 \%)$ of their patients required a VP shunt. The authors suggest that a more critical evaluation and tolerance of ventriculomegaly may decrease the need for shunt placement and will reduce shunt dependency in children with myelomeningocele, without worsening outcome.

In a study by St. George et al., limited by its small number of subjects, the authors examined 13 patients with multiple diagnoses who had undergone ETV (Table 1). ${ }^{23}$ 
Part 10: Ventricle size change as measure of effective treatment

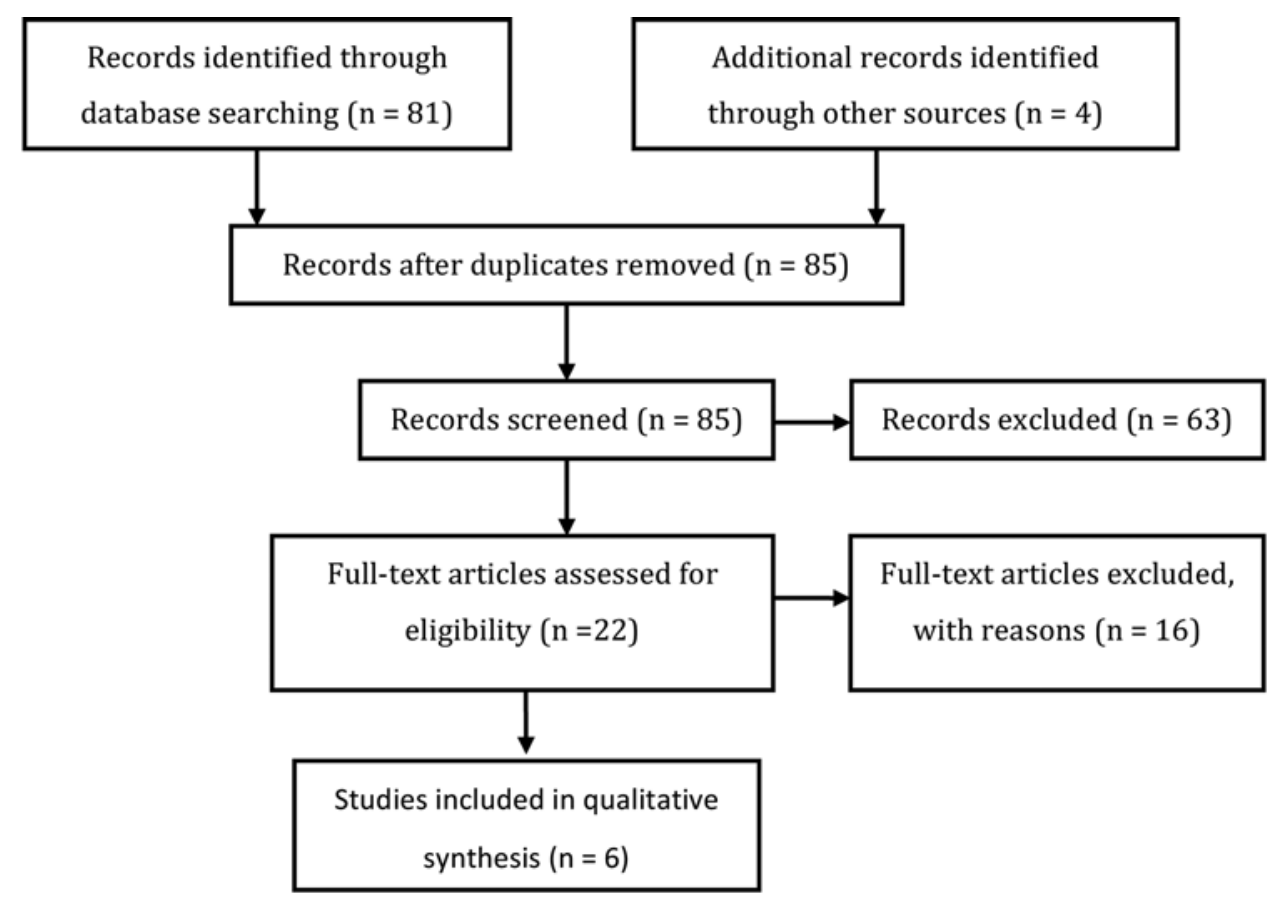

FIG. 1. Flowchart showing the process involved in identifying relevant literature.

The comparison of preoperative and postoperative ventricular volume was confined to patients in this treatment group. The authors found postoperative measurements of ventricular volume to be lower than measurements obtained preoperatively but higher than normalized values for patient ages and sexes. The pattern of change in ventricle size varied between a large ventricular volume group, which demonstrated a significant decrease at the 3to 6-month postoperative time point, and a small volume group, in which there was a much less steep reduction in ventricle size in the first 3-6 months. After that time period, the volume appeared to stabilize or fall slightly.

Two additional papers reported that ventricle size was not necessarily a predictor of outcome (Table 1). These 2 studies looked at ETV alone and found that in both infants and older children, reduction in ventricle size was not necessary to have a clinically effective treatment of hydrocephalus. Like the previously cited studies, these studies were retrospective, and both enrolled a small number of patients (Buxton et al.: $\mathrm{n}=27$; Kim et al.: $\mathrm{n}=$ 29 in whom neuroimaging studies were available). ${ }^{2,16}$

\section{Excluded Evidence}

The evidence reviewed was predominantly Class III. Those papers not used in the analysis were excluded for multiple reasons including the following: reports combining adult and pediatric patient populations without reporting pediatric patients separately; ${ }^{3,7,9-11,15}$ a review of other studies $;{ }^{20}$ and a technical report. ${ }^{21}$ Jain et al. ${ }^{14}$ reported the effect of valve design on repeated operation, not on effectiveness of treatment. Another paper described how to measure ventricles. ${ }^{19}$ Kombogiorgas et al. ${ }^{17}$ confined their evaluation to the question of ventricle size predicting the need for shunting after tumor resection in patients with posterior fossa tumors. The large study by Shankaran and colleagues $^{22}$ looked at the impact of vetriculomegaly on outcome, without expressly addressing the shunt status of the patients and was thus excluded. One article could not be retrieved for full-text review and was therefore excluded. ${ }^{1}$ The paper by Horbar et al. ${ }^{12}$ did not meet inclusion criteria due to enrollment of fewer than 10 patients. One by Choudhury ${ }^{5}$ was excluded because it did not report ventricle size as an outcome of interest and therefore did not report data to answer the clinical questions addressed in this section. Goumnerova and Frim ${ }^{10}$ reported a study including adults and children, but did not analyze the pediatric patients separately.

\section{Conclusions}

Recommendation: There is insufficient evidence to recommend a specific change in ventricle size as a measurement of effective treatment of hydrocephalus and as a measurement of the timing and effectiveness of treatments including ventriculoperitoneal shunts and third ventriculostomies. Strength of Recommendation: Level III, unclear clinical certainty.

The purpose of hydrocephalus treatment is to return the CSF and/or pressure within the brain of an affected infant or child to as normal a condition as possible. Resources to effect these changes are currently limited primarily to the use of a ventriculoperitoneal (VP) shunt or endoscopic third ventriculostomy (ETV). Intracranial pressure and its effect on brain function cannot easily be measured, and thus an alternate way of judging treatment effectiveness is necessary. The size of ventricles revealed by a number of imaging modalities, including ultrasonography, CT, and MR imaging, is frequently used as a measure of the effectiveness of intervention. Our evaluation of the evidence reveals that reliance on ventricle size 
TABLE 1: Ventricle size: summary of evidence*

\begin{tabular}{|c|c|c|c|}
\hline Authors \& Year & Study Description & $\begin{array}{l}\text { Data Class, Quality, } \\
\text { \& Reasons }\end{array}$ & Conclusion \\
\hline $\begin{array}{l}\text { Chakraborty et } \\
\text { al., } 2008\end{array}$ & $\begin{array}{l}\text { Single-center, } 10 \text {-yr retrospective review of } \\
\text { pts w/ MMC, excluding pts in whom primary } \\
\text { closure was performed elsewhere. } \\
\text { Shunt placed for symptomatic hydrocephalus, } \\
\text { severe hydrocephalus, or progression of } \\
\text { ventriculomegaly after closure. } 54 \text { cases } \\
\text { included; shunt required in } 28 \text { ( } 52 \%) \text {. } \\
\text { Evaluated shunt insertion, complications, \& } \\
\text { clinical outcomes. }\end{array}$ & $\begin{array}{l}\text { Class III } \\
\text { Single center, retrospective, } \\
\text { single cohort. } \\
\text { "Increasing ventriculomegaly } \\
\text { assessed by a neurora- } \\
\text { diologist w/ the neurosur- } \\
\text { geon. No specific imaging } \\
\text { measurement was used to } \\
\text { define hydrocephalus." }\end{array}$ & $\begin{array}{l}\text { Shunt insertion rates in pts w/ MMC lower than } \\
\text { previously published results ( } \& \text { similar to } \\
\text { those of in utero closure) when allowing mild } \\
\text { ventriculomegaly. }\end{array}$ \\
\hline Kim et al., 2000 & $\begin{array}{l}32 \text { children w/ ETV. Mean follow-up: } 19 \text { mos. } \\
\text { Postprocedural neuroimaging studies avail- } \\
\text { able in } 29 \text { pts. Outcomes: good in } 21 \text { pts \& } \\
\text { poor in } 8 \text { pts. } \\
\text { Ventricle size, edema, widening of sub- } \\
\text { arachnoid space, surgical changes in 3rd } \\
\text { ventricle examined. Floor cine-MR findings } \\
\text { studied btwn the } 2 \text { outcome groups. }\end{array}$ & $\begin{array}{l}\text { Class III } \\
\text { Retrospective study. }\end{array}$ & $\begin{array}{l}\text { Good outcomes group: } \\
\text { In } 11 \text { of } 16 \text { pts there was a decrease in ventricle } \\
\text { size } 1 \text { mo postop. } \\
\text { In } 5 \text { of } 16 \text { pts only minimal changes were } \\
\text { observed. } \\
\text { Ventricle size tended to decrease w/ time. } \\
\text { Changes in ventricle size could not predict surgi- } \\
\text { cal outcome completely alone. No correlation. }\end{array}$ \\
\hline $\begin{array}{l}\text { St. George et } \\
\text { al., } 2004\end{array}$ & $\begin{array}{l}\text { Single-center, } 13 \text { consecutive pts w/ hydro- } \\
\text { cephalus undergoing ETV studied, MR } \\
\text { images were reviewed, \& ventricle vol } \\
\text { calculated. } \\
\text { Preop vol } 207 \mathrm{~cm}^{3}, 1 \text { wk } 120 \mathrm{~cm}^{3}, 3 \text { mos } 104 \\
\mathrm{~cm}^{3}, 6 \text { mos } 119 \mathrm{~cm}^{3}, 12 \text { mos } 146 \mathrm{~cm}^{3}, 24 \\
\text { mos } 185 \mathrm{~cm}^{3} \text { (skewed because they did } \\
\text { not have many } 24 \text {-mo follow-ups, so it } \\
\text { was overly influenced by increases in } 13 \\
\text { pts who originally had large ventricles). } \\
\text { Decrease in size was more rapid in those } \\
\text { pts. w/ larger ventricles. }\end{array}$ & $\begin{array}{l}\text { Class III } \\
\text { Single center, no comparison } \\
\text { group. } \\
\text { Did not compare use of } \\
\quad \text { volumetric evaluation in pts } \\
\text { receiving shunts. }\end{array}$ & $\begin{array}{l}\text { Pts w/ moderate ventriculomegaly had a less } \\
\text { steep decrease in ventricle size in the first } \\
6 \text { mos after ETV than pts w/ large preop } \\
\text { ventricles. Steady-state vols were larger than } \\
\text { normal. }\end{array}$ \\
\hline $\begin{array}{l}\text { Warf et al., } \\
\quad 2009\end{array}$ & $\begin{array}{l}93 \text { pts, spina bifida. } \\
\text { Assessment of development \& ventricle size. } \\
55 \text { pts underwent ETV w/ CPC; } 19 \text { pts re- } \\
\text { ceived VP shunts; } 19 \text { received no Tx. }\end{array}$ & $\begin{array}{l}\text { Class III } \\
\text { Retrospective study. } \\
\text { Nonrandomized, noncon- } \\
\quad \text { trolled. }\end{array}$ & $\begin{array}{l}\text { No Tx group showed better development than } \\
\text { treated group. There was better receptive } \\
\text { communication in the ETV w/ CPC group than } \\
\text { in the VP shunt group ( } p=0.02 \text { ). } \\
\text { No difference in ventricle vol between the ETV } \\
\text { w/ CPC \& VP shunt groups. }\end{array}$ \\
\hline $\begin{array}{l}\text { Buxton et al., } \\
\quad 1998\end{array}$ & $\begin{array}{l}\text { Outcomes \& reasons for failure in ETVs per- } \\
\text { formed in children < } 1 \text { yr old: } 27 \text { total pts. } \\
\text { Postop ventricle size \& flow through stoma } \\
\text { documented. Comparison was performed } \\
\text { between successes \& failures ( } 21 \text { pts, } 77 \% \\
\text { of procedures). }\end{array}$ & $\begin{array}{l}\text { Class III } \\
\text { Retrospective review of pro- } \\
\text { spectively acquired data. }\end{array}$ & $\begin{array}{l}\text { Postop ventricle size was not an indicator of } \\
\text { success or failure. } \\
\text { Size does not matter. }\end{array}$ \\
\hline $\begin{array}{l}\text { Kulkarni et al., } \\
2000\end{array}$ & $\begin{array}{l}\text { Retrospective study of FOR (measure of ven- } \\
\text { tricle size) change post-ETV in comparing } \\
\text { successes \& failures. }\end{array}$ & $\begin{array}{l}\text { Class III } \\
\text { Retrospective case series. } \\
\text { Images evaluated by } 4 \text { observ- } \\
\text { ers, } 2 \text { blinded \& } 2 \text { un- } \\
\text { blinded, looking at ventricle } \\
\text { size, flow void, periven- } \\
\text { tricular edema, \& CSF in } \\
\text { subarachnoid space. } \\
\text { Comparison w/ 2-tailed t-test }\end{array}$ & $\begin{array}{l}\text { ETV failures: mean postop reduction in ventricle } \\
\text { size was } 7 \% \text {. } \\
\text { ETV clinical successes: mean postop reduction } \\
\text { in ventricle size was } 16 \% \text { (reduction signifi- } \\
\text { cantly greater). } \\
\text { Decreased FOR in all pts. Slightly more in the } \\
\text { successful cases, but not when compared to } \\
\text { normal ventricles. (Ventricles do not return to } \\
\text { normal even after successful ETV.) }\end{array}$ \\
\hline
\end{tabular}

${ }^{*} \mathrm{MMC}=$ myelomeningocele; $\mathrm{pts}=$ patients; $\mathrm{Tx}=$ treatment.

alone, as a demonstration of treatment effectiveness, is not supported by the available evidence. Unfortunately, there are no other direct methods currently in general use.
Certainly, developmental progress is worth monitoring, but this is more difficult to accomplish for routine postsurgical evaluations. 


\section{Part 10: Ventricle size change as measure of effective treatment}

This systematic review and evidence-based guideline demonstrates that the objective measurement of ventricle size by simple methods such as the frontal and occipital horn ratio (FOR) has not proven to be a reliable benchmark of effectiveness. Clinical outcome ascertained by the neurosurgeon and team is still the most accepted and useful evaluation, surpassing other more "objective" standards.

\section{Acknowledgments}

We acknowledge the American Association of Neurological Surgeons (AANS)/Congress of Neurological Surgeons (CNS) Joint Guidelines Committee for the members' reviews, comments, and suggestions; Laura Mitchell, Guidelines Project Manager for the CNS, for her contributions; Pamela Shaw, research librarian, for her assistance with the literature searches; Kevin Boyer for his assistance with data analysis; and Sue Ann Kawecki for her assistance with editing.

\section{Disclosure}

The systematic review and evidence-based guidelines were funded exclusively by the CNS and AANS Pediatric Section, which received no funding from outside commercial sources to support the development of this document.

Conflict(s) of Interest: None. All Task Force members declared any potential conflicts of interest prior to beginning work on this evidence review.

Author contributions to the study and manuscript preparation include the following. Conception and design: AANS/CNS Joint Section on Pediatrics. Acquisition of data: all authors. Analysis and interpretation of data: all authors. Drafting the article: all authors. Critically revising the article: all authors. Reviewed submitted version of manuscript: all authors. Approved the final version of the manuscript on behalf of all authors: Flannery. Administrative/technical/ material support: all authors. Study supervision: Flannery.

\section{References}

1. Bajpai M, Kataria R, Bhatnagar V, Agarwala S, Gupta DK, Bharadwaj M, et al: Management of hydrocephalus. Indian J Pediatr 64 (6 Suppl):48-56, 1997

2. Buxton N, Macarthur D, Mallucci C, Punt J, Vloeberghs M: Neuroendoscopic third ventriculostomy in patients less than 1 year old. Pediatr Neurosurg 29:73-76, 1998

3. Buxton N, Turner B, Ramli N, Vloeberghs M: Changes in third ventricular size with neuroendoscopic third ventriculostomy: a blinded study. J Neurol Neurosurg Psychiatry 72:385-387, 2002

4. Chakraborty A, Crimmins D, Hayward R, Thompson D: Toward reducing shunt placement rates in patients with myelomeningocele. J Neurosurg Pediatr 1:361-365, 2008

5. Choudhury AR: Avoidable factors that contribute to the complications of ventriculoperitoneal shunt in childhood hydrocephalus. Childs Nerv Syst 6:346-349, 1990

6. Cinalli G, Spennato P, Ruggiero C, Aliberti F, Zerah M, Trischitta V, et al: Intracranial pressure monitoring and lumbar puncture after endoscopic third ventriculostomy in children. Neurosurgery 58:126-136, 2006

7. Feng H, Huang G, Liao X, Fu K, Tan H, Pu H, et al: Endoscopic third ventriculostomy in the management of obstructive hydrocephalus: an outcome analysis. J Neurosurg 100:626633, 2004

8. Flannery AM, Mitchell L: Pediatric hydrocephalus: systematic literature review and evidence-based guidelines. Part 1: Introduction and methodology. J Neurosurg Pediatr 14:3-7, 2014

9. Fukuhara T, Vorster SJ, Luciano MG: Risk factors for failure of endoscopic third ventriculostomy for obstructive hydrocephalus. Neurosurgery 46:1100-1111, 2000
10. Goumnerova LC, Frim DM: Treatment of hydrocephalus with third ventriculocisternostomy: outcome and CSF flow patterns. Pediatr Neurosurg 27:149-152, 1997

11. Hommet C, Cottier JP, Billard C, Perrier D, Gillet P, De Toffol B, et al: MRI morphometric study and correlation with cognitive functions in young adults shunted for congenital hydrocephalus related to spina bifida. Eur Neurol 47:169-174, 2002

12. Horbar JD, Walters CL, Philip AG, Lucey JF: Ultrasound detection of changing ventricular size in posthemorrhagic hydrocephalus. Pediatrics 66:674-678, 1980

13. Jack CR Jr, Kelly PJ: Stereotactic third ventriculostomy: assessment of patency with MR imaging. AJNR Am J Neuroradiol 10:515-522, 1989

14. Jain H, Natarajan K, Sgouros S: Influence of the shunt type in the difference in reduction of volume between the two lateral ventricles in shunted hydrocephalic children. Childs Nerv Syst 21:552-558, 2005

15. Jindal A, Mahapatra AK: Correlation of ventricular size and transcranial Doppler findings before and after ventricular peritoneal shunt in patients with hydrocephalus: prospective study of 35 patients. J Neurol Neurosurg Psychiatry 65:269-271, 1998

16. Kim SK, Wang KC, Cho BK: Surgical outcome of pediatric hydrocephalus treated by endoscopic III ventriculostomy: prognostic factors and interpretation of postoperative neuroimaging. Childs Nerv Syst 16:161-169, 2000

17. Kombogiorgas D, Natarajan K, Sgouros S: Predictive value of preoperative ventricular volume on the need for permanent hydrocephalus treatment immediately after resection of posterior fossa medulloblastomas in children. J Neurosurg Pediatr 1:451-455, 2008

18. Kulkarni AV, Drake JM, Armstrong DC, Dirks PB: Imaging correlates of successful endoscopic third ventriculostomy. J Neurosurg 92:915-919, 2000

19. O'Hayon BB, Drake JM, Ossip MG, Tuli S, Clarke M: Frontal and occipital horn ratio: a linear estimate of ventricular size for multiple imaging modalities in pediatric hydrocephalus. Pediatr Neurosurg 29:245-249, 1998

20. Rekate HL: To shunt or not to shunt: hydrocephalus and dysraphism. Clin Neurosurg 32:593-607, 1985

21. Schroeder HW, Oertel J, Gaab MR: Endoscopic aqueductoplasty in the treatment of aqueductal stenosis. Childs Nerv Syst 20:821-827, 2004

22. Shankaran S, Koepke T, Woldt E, Bedard MP, Dajani R, Eisenbrey $\mathrm{AB}$, et al: Outcome after posthemorrhagic ventriculomegaly in comparison with mild hemorrhage without ventriculomegaly. J Pediatr 114:109-114, 1989

23. St. George E, Natarajan K, Sgouros S: Changes in ventricular volume in hydrocephalic children following successful endoscopic third ventriculostomy. Childs Nerv Syst 20:834-838, 2004

24. Warf B, Ondoma S, Kulkarni A, Donnelly R, Ampeire M, Akona J, et al: Neurocognitive outcome and ventricular volume in children with myelomeningocele treated for hydrocephalus in Uganda. Clinical article. J Neurosurg Pediatr 4:564-570, 2009

25. Wilcock DJ, Jaspan T, Worthington BS, Punt J: Neuro-endoscopic third ventriculostomy: evaluation with magnetic resonance imaging. Clin Radiol 52:50-54, 1997

Manuscript submitted June 25, 2014.

Accepted July 7, 2014.

Please include this information when citing this paper: DOI: 10.3171/2014.7.PEDS14330.

Address correspondence to: Ann Marie Flannery, M.D., Department of Neurological Surgery, Saint Louis University, 3565 Vista Ave., St. Louis, MO 63110. email: flanneam@slu.edu. 